\title{
Perceived parenting attitudes in relation to ADHD symptoms and aggressive behaviors in a sample of Egyptian children with ADHD
}

Hanan Azzam ${ }^{1}$, Haytham Hasan ${ }^{2^{*}}$ (D, Mahmoud Elhabiby ${ }^{1}$, Reem El Ghamry ${ }^{1}$, Mona Mansour ${ }^{1}$ and Mohammed Elhamshary ${ }^{3}$

\begin{abstract}
Background: Externalizing behaviors are common in children with attention-deficit hyperactivity disorder (ADHD). This study was aiming to investigate the perceived parenting attitudes in children with ADHD and their correlates to the severity of symptoms and associated aggressive behaviors in those children. Accordingly, 140 children with ADHD were assessed using Mini International Neuropsychiatric Interview for Children; Conners' Parent Rating ScaleRevised, Long Version; the problem scale of the Child Behavior Checklist for ages 4-18; and the Perceived Parenting Attitude Scale.

Results: Assessment of associated behavioral problems in the participants revealed the presence of significant aggressive and externalizing problems. The participants perceived a similar attitude between their mothers and fathers. No significant association is found between severity of ADHD symptoms and perceived parenting attitudes, while consistency in parenting in both mothers and fathers was positively correlated to the aggressive behaviors of the participants.

Conclusions: Aggression is a common symptom associated with ADHD that should be identified and addressed. Although the current study has revealed that consistency in parenting is positively correlated to the aggression in ADHD children, yet children with ADHD might have a positive illusory bias in their social self-perceptions making it difficult to account for the reliability of their perceived parenting attitudes; hence, it remains to be clarified whether perceived parents' attitudes are attributed to children's aggression or to children's perception caused by the previously mentioned illusory bias. For future research, it is highly recommended to assess parenting from the parents' and their children's points of view.
\end{abstract}

Keywords: ADHD, Aggression, Externalizing behaviors, Perceived parenting attitude, Positive illusory bias

\footnotetext{
* Correspondence: haythamhassan666@gmail.com

${ }^{2}$ Faculty of Medicine, Helwan University, Helwan, Egypt

Full list of author information is available at the end of the article
}

\section{Springer Open}

(- The Author(s). 2021 Open Access This article is licensed under a Creative Commons Attribution 4.0 International License, which permits use, sharing, adaptation, distribution and reproduction in any medium or format, as long as you give appropriate credit to the original author(s) and the source, provide a link to the Creative Commons licence, and indicate if changes were made. The images or other third party material in this article are included in the article's Creative Commons licence, unless indicated otherwise in a credit line to the material. If material is not included in the article's Creative Commons licence and your intended use is not permitted by statutory regulation or exceeds the permitted use, you will need to obtain permission directly from the copyright holder. To view a copy of this licence, visit http://creativecommons.org/licenses/by/4.0/. 


\section{Background}

Attention-deficit hyperactivity disorder (ADHD) is a neurodevelopmental disorder beginning in childhood with a recurrent pattern of inattention or hyperactivityimpulsiveness outside the range of developmental expectations which can affect the functioning of individuals regarding academics and social functioning [1]. Epidemiological studies show that ADHD is a widespread condition that affects 6.7 to $7.8 \%$ of children worldwide [2]. In Arab countries, this incidence is higher, reaching 9.4-21.8\% in Egypt [3, 4] and 11.6\% in Saudi Arabia [5]. Comorbid conduct disorder is present in up to $30-50 \%$ of children with ADHD, while oppositional defiant disorder is diagnosed in about 35\% of children with ADHD [6].

Childhood ADHD serves as a burden that increases the probability of parenting issues typically associated with problems of child opposition/behavior. In other words, a child's high level of inattention or impulsivity imposes multiple demands on parents and increases the risk of parents responding with less than ideal consistency, over-reactive discipline, or excessive withdrawal from the child. Both the ADHD of the child and these parenting issues combine to provide the necessary conditions for the creation of oppositional/conduct disorders [7].

Several studies have examined parenting styles in patients with ADHD, yet the study of perceived parenting attitude in patients with ADHD in correlation with aggressive behaviors associated with ADHD has received limited research attention especially in the national literatures; this is an aspect of the issue that might provide a better knowledge of ADHD psychopathology if highlighted. Hence, this study was conducted to assess how children with ADHD perceive their families' parenting attitudes and whether these attitudes correlate with aggressive behaviors associated with ADHD or not.

\section{Methods}

1- A convenient sample consisted of 140 children with ADHD aged 6-12 years was recruited from the child psychiatry clinic in the Institute of Psychiatry - Ain Shams University Hospitals. Children with comorbid psychiatric disorders rather than disruptive behavior disorders, children with an IQ score below 90, or children living with single mothers or single fathers were excluded.

2- Information regarding the sociodemographic profile of the enrolled subjects was collected using the Socioeconomic Status Scale [8] which is the modified version of the scale of Fahmy and ElSherbini, originally published in 1983 and was the most commonly used scale to determine the socioeconomic status in health research in Egypt [9].
3- All participants were subjected to the following:

- Clinical psychiatric interviewing. ADHD was diagnosed according to DSM-5 [1].

- Mini International Neuropsychiatric Interview for Children (M.I.N.I. Kid) which is a short structured diagnostic interview for DSM-IV and ICD-10 psychiatric disorders [10]. It was used to exclude other psychiatric co-morbidities. The Arabic-translated version was used in many Arabic countries' studies and was validated with good validity and reliability [11].

- Assessment of intelligence quotient (IQ) using the Arabic version of the Stanford-Binet Intelligence Scale, 5th Edition (SB5) to exclude children with below-average IQ $[12,13]$.

- Assessment of severity of their ADHD symptoms using the Arabic version of the Conners' Parent Rating Scale-Revised, Long Version (CPRS-R-L) $[14,15]$.

- Assessment of associated externalizing behaviors using the Arabic version of the problem scale of the Child Behavior Checklist for ages 4-18 (CBCL 4-18) [15, 16].

- Assessment using the Perceived Parenting Attitude Scale (PPAS). This scale was developed in Egypt by Sobhy [17]. It is an 80-item questionnaire administered to children to assess how they perceive their parents' parenting attitudes. It is designed for measuring four domains: (i) acceptance versus rejection, (ii) encouraging independence versus dependence on parents, (iii) consistency in parents' attitude versus inconsistency, and (iv) equality in treatment versus sense of inequality in respect to their sibs. Each domain is represented by ten questions for the father and ten for the mother. Two points for answers indicating good parenting style, zero points for answers indicating poor parenting style, and one point when the child is uncertain. This means that each domain has a maximum score of twenty and a minimum score of zero. All domains are summed up to provide the total score. For each domain and the total score, higher scores indicate good perceived parenting attitude and lower scores indicate poor perceived parenting attitude [17].

4- By the end of the study, data were analyzed using SPSS computer package version 17 (SPSS, Chicago, IL, USA).

\section{Results}

A total of 140 children with ADHD were enrolled in the study. They were 110 males and 30 females. Their mean age was $8.2( \pm 2.4)$. Regarding socioeconomic class, $4.3 \%$ 
of them were of very low socioeconomic class, $51.4 \%$ were of low class, and $44.3 \%$ were of moderate class.

Assessment of ADHD symptoms using CPRS-R-L revealed the presence of significant problems in the following domains: oppositional, cognitive problems and inattention, hyperactivity, Conners' ADHD Index, Conners' Global Index: restless-impulsive, Conners' Global Index: emotional lability, Conners' Global Index: total, DSM-IV: inattentive, DSM-IV: hyperactivity-impulsive, and DSM-IV: total score as shown in Fig. 1.

Assessment of behavioral problems using the problem scale of CBCL revealed the presence of significant attentional problems and externalizing problems while the aggressive behaviors were within the borderline range as shown in Fig. 2.

Comparing perceived parenting attitudes between mothers and fathers using unpaired $t$ test failed to find any statistically significant difference between mothers and fathers in the four assessed domains of the parenting attitude, i.e., the studied children perceived comparable attitude from mothers and fathers. The highest perceived parenting attitude was acceptance while encouraging independence was the lowest perceived parenting attitude as shown in Table 1.

Examining the correlation between perceived parenting attitudes and severity of ADHD symptoms using Pearson correlation coefficient revealed the absence of any statistically significant correlation as seen in Table 2 .

Examining the correlation between perceived parenting attitudes and disruptive behaviors using the Pearson correlation coefficient revealed the presence of statistically significant positive correlations between the perception of the father and the mother as being consistent in treating children with aggressive behavior and externalizing problems as shown in Table 3.

\section{Discussion}

In the context of developmental psychopathology, parenting is considered one of the contributors to psychopathology from childhood to adulthood. Previous studies focused mainly on parenting, while less have discussed perceived parenting attitudes; hence, the current study investigated the association between ADHD symptoms and the associated behavioral problems in ADHD children and their perceived parenting attitudes.

Assessment of ADHD symptoms in the studied group using Conner's Parent Rating Scale revealed the presence of significant oppositional, inattentive and hyperactivity, and mild social problems. Meanwhile, there was no significant anxiety, perfectionism, or psychosomatic symptoms. Regarding parental attitudes in the current study, ADHD children perceived similar attitudes between the mothers and fathers in the 4 domains of the parenting attitude scale (consistency-acceptance-equality-independence). The highest perceived parenting attitude was acceptance while the lowest perceived parenting attitude is independence. Our results failed to find an association between the severities of ADHD symptoms in the studied children with their perceived parenting attitudes.

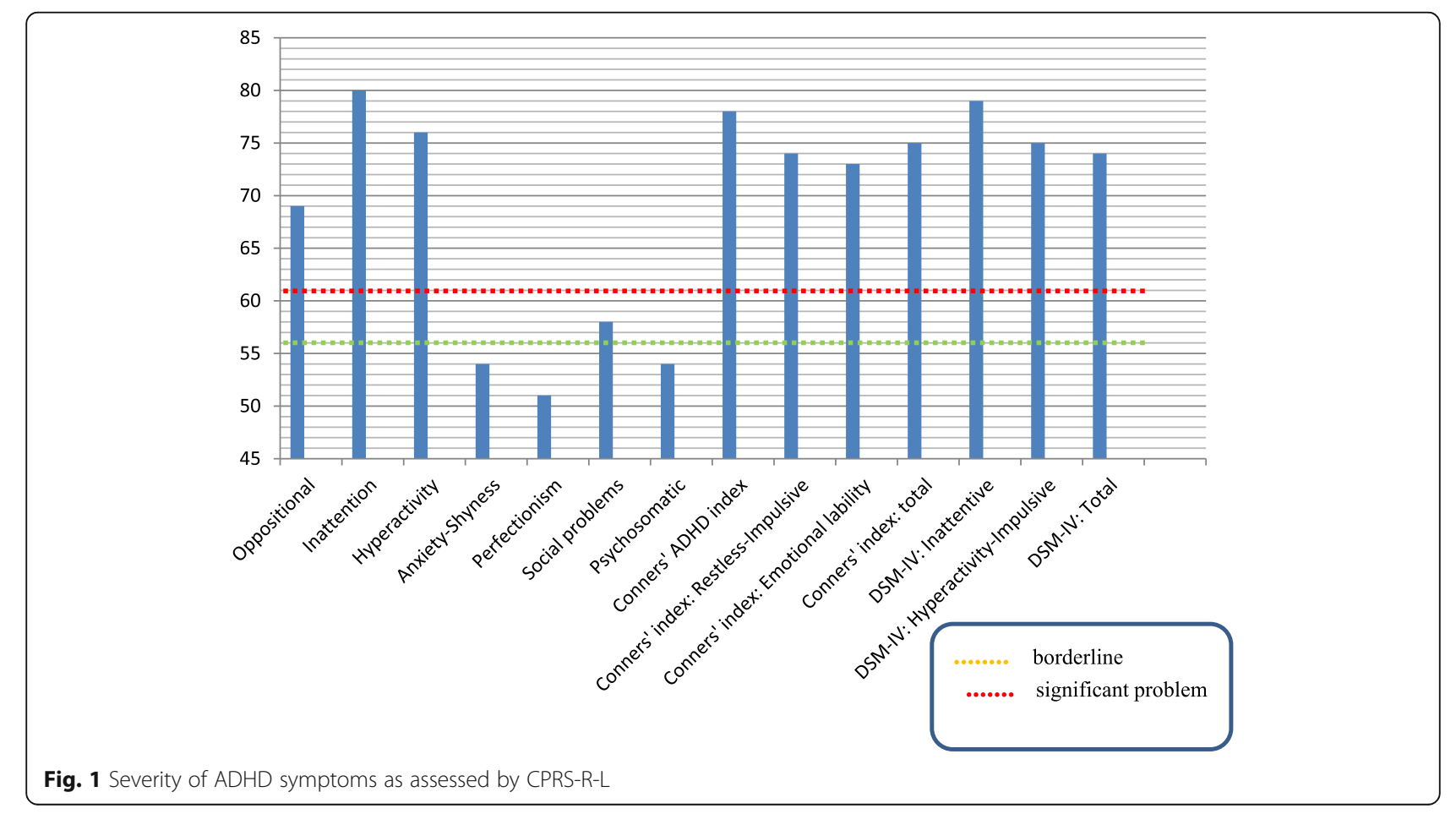




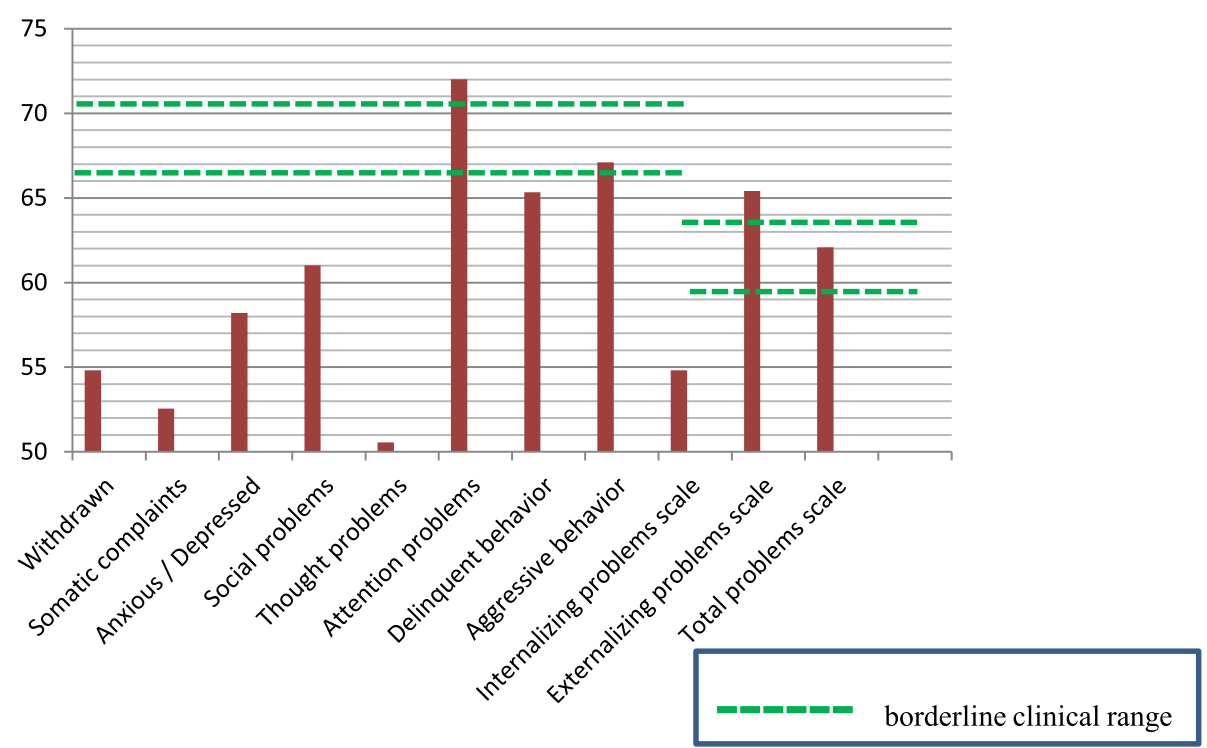

Fig. 2 Severity of behavioral problems as assessed by $C B C L$

Other studies reported different findings from ours; an Eastern study compared 296 ADHD children with 229 controls regarding the father's parenting style and perceived family support. Compared to controls, children with ADHD experienced less affectionate/care and more paternal overprotection and authoritarian controls and perceived less family support than controls [18]. In their complementary study examining the role of mothering in ADHD, Gau and Chang found that children with ADHD received less affection/care and greater maternal overprotection and control and perceived less family support than non-ADHD children. Child's report shows that child's inattention and comorbidity were correlated significantly with low affection/care from the mother and high control, while hyperactivity-impulsivity was correlated significantly with overprotection, and child's inattention and comorbidity were correlated significantly with diminished family support and disrupted motherchild interactions [19].

Earlier studies conducted by Johnston [20], Keown and Woodword [21], Gerdes et al. [22], and Ellis and Nigg [23] revealed that parents of ADHD children who were perceived by their children as more assertive, uninvolved, and inconsistent faced more severe ADHD

Table 1 ADHD children's perceived parenting attitudes from both mothers and fathers

\begin{tabular}{llll}
\hline PPAS & Mother & Father & $P$ value \\
\hline Independence & $8.69 \pm 2.89$ & $8.55 \pm 2.94$ & 0.689 \\
Consistency & $10.55 \pm 3.72$ & $10.73 \pm 4.09$ & 0.715 \\
Acceptance & $15.23 \pm 3.45$ & $14.73 \pm 3.88$ & 0.269 \\
Equality & $10.64 \pm 2.82$ & $10.7 \pm 2.63$ & 0.856 \\
\hline
\end{tabular}

symptoms than compared parents [20-23]. Probably, the explanation of the variation between the results of the current study and the formerly discussed studies comes from assessing different aspects of parenting in those studies rather than aspects assessed in the current study.

In the current study, assessment of associated behavioral problems of the ADHD children using the Child Behavior Checklist revealed the presence of attentional problems as expected, as well as the presence of significant aggressive and externalizing problems in $60.7 \%$ of the children. These results come in agreement with the findings of previous studies such as those conducted by Harty et al. [24] and Zenglein et al. [25]. According to Harty et al. [24], among ADHD comorbidities, disruptive behavior disorders are the most prevalent as conduct disorder is present in up to $30-50 \%$ of children with ADHD, while oppositional defiant disorder is diagnosed in about 35\% of children with ADHD [6].

On examining the correlation between aggressive and externalizing behavior in the ADHD children with their perceived parenting attitude in the current study, it was expected that inconsistency will be associated with disruptive behaviors; surprisingly, consistency in parenting in both mothers and fathers was positively correlated to the disruptive behaviors in ADHD children. These unexpected inconvenient findings could be explained in light of recall bias that is expected to be present in ADHD children or in light of their illusory bias (will be discussed later).

Again, other studies reported different findings; in their study aiming for exploring the association between parenting styles and behavioral problems in 22 Brazilian ADHD children, Teixeira and her colleagues [26] 
Table $2 P$ values of correlations between perceived parenting attitudes and severity of ADHD symptoms

\begin{tabular}{|c|c|c|c|c|c|c|c|c|}
\hline \multirow{2}{*}{$\begin{array}{l}\text { PPAS } \\
\text { CPRS-R-L }\end{array}$} & \multicolumn{4}{|c|}{ Perceived fathers' parenting attitudes } & \multicolumn{4}{|c|}{ Perceived mothers' parenting attitudes } \\
\hline & Independence & Consistency & Acceptance & Equality & Independence & Consistency & Acceptance & Equality \\
\hline Oppositional & 0.164 & 0.351 & 0.072 & 0.056 & 0.297 & 0.552 & 0.602 & 0.249 \\
\hline Inattention & 0.788 & 0.176 & 0.34 & 0.984 & 0.455 & 0.687 & 0.226 & 0.666 \\
\hline Hyperactivity & 0.678 & 0.408 & 0.29 & 0.384 & 0.65 & 0.651 & 0.438 & 0.545 \\
\hline Conners' ADHD Index & 0.972 & 0.051 & 0.264 & 0.852 & 0.568 & 0.383 & 0.209 & 0.78 \\
\hline Conners' Index: restless-impulsive & 0.596 & 0.585 & 0.306 & 0.146 & 0.666 & 0.919 & 0.403 & 0.507 \\
\hline Conners' Index: emotional lability & 0.051 & 0.874 & 0.293 & 0.659 & 0.079 & 0.406 & 0.897 & 0.96 \\
\hline Conners' Index: total & 0.648 & 0.196 & 0.551 & 0.166 & 0.833 & 0.794 & 0.595 & 0.428 \\
\hline DSM-IV: inattentive & 0.67 & 0.19 & 0.369 & 0.993 & 0.814 & 0.686 & 0.245 & 0.899 \\
\hline DSM-IV: hyperactivity-impulsive & 0.471 & 0.675 & 0.186 & 0.2 & 0.527 & 0.864 & 0.32 & 0.606 \\
\hline DSM-IV: total & 0.578 & 0.176 & 0.659 & 0.098 & 0.777 & 0.72 & 0.793 & 0.286 \\
\hline
\end{tabular}

reported the presence of a significant positive correlation between parental inconsistency and aggressive and externalizing problems. The authors emphasized that inadequate parental strategies mainly inconsistent punishment are associated with several patterns of behavioral problems, mainly of the externalizing type [26]. In the same year, 2015, $\mathrm{Ni}$ and $\mathrm{Gau}$ [27] investigated the severity of ADHD symptoms and externalizing symptoms in relation to perceived parenting in adolescents with ADHD. They observed that correlations of ADHD with externalizing symptoms were inversely linked to the level of care of the father and mother, while the association of ADHD with wide-ranging comorbid conduct or oppositional defiant symptoms was related positively to the level of mothers' and fathers' overprotection/control [27].

In an earlier study exploring parenting practices in families of 149 ADHD children, Pfiffner et al. [28] found a significant correlation between maternally negative/ineffective discipline and oppositional defiant disorder and conduct disorder. The lack of mothers' warmth and involvement and paternal negative/ineffective discipline were associated significantly with comorbid conduct disorder, but not with the oppositional defiant disorder. According to the authors, consistent discipline appears to be important for addressing comorbid oppositional defiant disorder and conduct disorder [28].

In spite of the previous studies contradicting the current study results, other studies came in agreement with the results. In an American study conducted by Gerdes and colleagues [29], perceived parent-child relationship quality was examined for 142 boys with ADHD and 55 non-ADHD control boys. Parent perceptions were also investigated. Parents of ADHD boys have more negative perceptions for their relationships with their kids than parents of non-ADHD boys. Interestingly enough, ADHD boys did not differ from nonADHD boys in their views of the relation with their parents, considering these gaps in parental perceptions. Furthermore, when perceptions of ADHD boys were directly compared to their parents' perceptions, ADHD boys' reports were positively enhanced relative to those of control parent-child dyads. These findings can be considered as evidence for a positive illusory bias in the social self-perceptions of children with ADHD [29].

Table 3 Correlation between perceived parenting attitudes and disruptive behaviors in ADHD children

\begin{tabular}{|c|c|c|c|c|c|}
\hline \multirow{2}{*}{$\frac{\mathrm{CBCL}}{\mathrm{PPAS}}$} & & \multicolumn{2}{|c|}{ Aggressive behaviors } & \multicolumn{2}{|c|}{ Externalizing problems } \\
\hline & & $P$ value & Pearson correlation & $P$ value & Pearson correlation \\
\hline \multirow[t]{4}{*}{ Father } & Independence & .184 & -.116 & .171 & -.12 \\
\hline & Consistency & $.000 *$ & $.301^{* *}$ & $.001^{*}$ & .282 \\
\hline & Acceptance & .111 & -.139 & .349 & -.082 \\
\hline & Equality & .409 & -.072 & .259 & -.099 \\
\hline \multirow[t]{4}{*}{ Mother } & Independence & .18 & -.118 & .175 & -.119 \\
\hline & Consistency & $.000 *$ & $.315^{* *}$ & $.002 *$ & .267 \\
\hline & Acceptance & .904 & -.011 & .384 & .076 \\
\hline & Equality & .713 & -.032 & .597 & -.046 \\
\hline
\end{tabular}

* $P$ value less than 0.05

**Medium to large correlation 
Positive illusory bias (PIB) is a concept that imposes itself during studying self-perception; it refers to displaying self-perceptions that are over-optimistic relative to external competence metrics [30], whereas social positive illusory bias in children denotes overestimating their social approval in contrast to external criteria, as adults' scoring [31]. Remarkably, Hoza and her colleagues [32] noticed that, especially after disappointment, ADHD boys overestimate their social self-perceptions. The authors explained that ADHD children may feel a need to exaggerate their perceptions of the relationships with their parents, possibly due to frequent unpleasant experiences with their parents [32]. Diener and Milich [33] postulated this might act as a self-protective mechanism for children with ADHD.

In other words, along with other challenges ADHD children face, bad relationships with their parents can be more they can deal with at one time. As a consequence, in an attempt to prevent them from feeling bad about themselves and their families, they provide exaggerated expectations of their relationships with their parents. Maybe as a result of poor metacognitive abilities, these children are less conscious of the conflict in their relationships with others.

Indeed, a growing body of literature emphasizes the presence of this PIB in ADHD children and explores its causes, functions, future predictors mainly maladjustment, differences between implicit and explicit PIB, its relation with their social behaviors and their executive functions, and its relation with other comorbidities [31, 34-41].

Taking PIB into account, findings reported by Hoza and her colleagues [42] can be explained. The researchers analyzed the self-perceptions of ADHD children in relation to the scores of teachers of boys with ADHD with comorbid aggression or without together with non-ADHD boys. Their study found that all ADHD subgroups exaggerated their ability considerably more than the control non-ADHD group, in relation to teachers' scores, in the scholastic, social, and behavioral domains. ADHD boys with aggression, however, overrated their abilities within the social domain significantly more than ADHD boys without aggression did. Social competence is a domain that would mostly be influenced by aggressive behavior. Moreover, estimations of the performance in other domains where aggression mostly has less or no effect, such as physical appearance, were not influenced by the presence of comorbid aggression [42]. In a research that involved both boys and girls with ADHD, a similar trend was observed, giving further support to the results [43].

In light of PIB and social PIB in ADHD children, findings of the current study could be viewed, perceiving exactly the same attitude from mothers and fathers, acceptance being the highest attitude perceived from parents, absence of association between severity of ADHD symptoms and perceived parenting attitudes, and finally the presence of this illogical significant positive correlation between aggression in ADHD children with consistent parental attitudes, whereas it is expected that negative parenting attitudes positively correlate with severity of ADHD symptoms and associated aggression in those children.

\section{Limitations}

To the best of our knowledge, this is one of the very few studies in the Middle East investigating the perceived parenting attitudes in relation to aggression in children with ADHD. The use of a valid reliable tool in the diagnosis of ADHD in the form of M.I.N.I. Kid strengthens the results, while using $\mathrm{CBCL}-\mathrm{a}$ non-diagnostic toolfor the assessment of associated aggressive and externalizing behaviors minimizes missing disruptive behavior disorder cases with sub-threshold symptoms. Nevertheless, some methodological limitations should be put in mind while analyzing the results. First, the findings should not be generalized due to the absence of a randomization sampling technique, recruiting the whole sample from only one center rather than multiple centers, and finally being a clinic-based sample consisted mostly of severe cases. Second, parenting attitudes from the parent's point of view were not assessed. This could have help confirm the suspected illusory bias of the ADHD children. Third, lying has not been excluded, which could be a potential cause of the unexpected results.

\section{Conclusions}

Findings of the current study indicate that children with ADHD perceive similar parenting attitudes from both fathers and mothers. The study further suggests that children with ADHD have PIB in their social self-perceptions making it difficult to account for the reliability of their perceived parenting attitudes, hence affecting the reliability of correlations between the children's symptoms and their perceived parenting attitudes. For future research, it is highly recommended to assess parenting from the parents' and their children's points of view. As little is understood about the predictive factors for aggression in ADHD children, studying individual differences in those children and their families is recommended in future trials. From a clinical perspective, since aggression is one of the common symptoms associated with ADHD, it needs to be clinically assessed and to be considered while tailoring a management plan. 


\section{Abbreviations}

ADHD: Attention-deficit hyperactivity disorder; CBCL 4-18: Child Behavior Checklist for ages 4-18; CPRS-R-L: Conners' Parent Rating Scale-Revised, Long Version; DSM-5: Diagnostic and Statistical Manual of Mental Disorders, 5th Edition; DSM-IV: Diagnostic and Statistical Manual of Mental Disorders, 4th Edition; FMASUREC: Faculty of Medicine-Ain Shams University Research Ethics Committee; ICD-10: International Classification of Diseases, Tenth Revision; IQ: Intelligence quotient; M.I.N.I. Kid: Mini International Neuropsychiatric Interview for Children; PIB: Positive illusory bias; PPAS: Perceived Parenting Attitude Scale; SB5: Stanford-Binet Intelligence Scale, 5th Edition

\section{Acknowledgements}

The authors would like to express gratitude to the whole staff of the child psychiatry clinic in the Institute of Psychiatry - Ain Shams University Hospitals for being cooperative with the research team.

\section{Authors' contributions}

HA proposed the research idea and design. $\mathrm{HH}$ contributed to developing the research idea, study methodology, and writing of the manuscript. ME helped in developing the study methodology and editing of the manuscript. RE helped in developing the study methodology and revising the data analysis and helped in the interpretation and editing of the manuscript. MM participated in the concept and design of the study. ME collected the data, performed the data analysis, and contributed to the interpretation and editing of the manuscript. All authors read and approved the final manuscript.

\section{Funding}

This research did not receive any specific grant from funding agencies in the public, commercial, or not-for-profit sectors.

\section{Availability of data and materials}

All data were accessible by the Internet as shown in the details of the "References" section.

\section{Ethics approval and consent to participate}

The current study has been approved by the Faculty of Medicine-Ain Shams University Research Ethics Committee (FMASUREC). The committee's reference number is not available. A written informed consent was obtained from the participants' parents.

\section{Consent for publication}

Not applicable.

\section{Competing interests}

There is no conflict of interests.

\section{Author details}

${ }^{1}$ Faculty of Medicine, Ain Shams University, Cairo, Egypt. ${ }^{2}$ Faculty of Medicine, Helwan University, Helwan, Egypt. ${ }^{3}$ Northumberland Tyne and Wear NHS Trust: Cumbria Northumberland Tyne and Wear NHS Foundation Trust, Newcastle upon Tyne, UK.

\section{Received: 26 November 2020 Accepted: 27 January 2021}

\section{Published online: 22 April 2021}

\section{References}

1. American Psychiatric Association (2013) Diagnostic and statistical manual of mental disorders: DSM-5, 5th edn. American Psychiatric Publishing, Inc., Arlington

2. Thomas R, Sanders S, Doust J, Beller E, Glasziou P (2015) Prevalence of attention-deficit/hyperactivity disorder: a systematic review and metaanalysis. Pediatrics 135(4):e994-e1001

3. EL-Gendy SD, El-Bitar EA, El-Awady MA, Bayomy HE, Agwa EM. Attentiondeficit/hyperactivity disorder: prevalence and risk factors in Egyptian primary school children. The Egyptian Journal of Community Medicine2017;35(1):1-16.

4. Bishry Z, Ramy HA, El-Shahawi HH, El-Sheikh MM, El-Missiry AA, El-Missiry MA (2018) Screening for ADHD in a sample of Egyptian adolescent schoo students. J Atten Disord 22(1):58-65
5. Homidi M, Obaidat Y, Hamaidi D. Prevalence of attention deficit and hyperactivity disorder among primary school students in Jeddah city, KSA. Life Sci J2013; 10(3): 280-285.

6. Harty SC, Miller CJ, Newcorn JH, Halperin JM (2009) Adolescents with childhood ADHD and comorbid disruptive behavior disorders: aggression, anger and hostility. Child Psychiatry Hum Dev 40(1):85-97

7. Johnston C, Jassy JS (2007) Attention-deficit/hyperactivity disorder and oppositional/conduct problems: links to parent-child interactions. J Can Acad Child Adolesc Psychiatry 16(2):74-79

8. El-Gilany A, El-Wehady A, El-Wasify M (2012) Updating and validation of the socioeconomic status scale for health research in Egypt. East Mediterr Health J 18(9):962-968

9. Fahmy S, El-Sherbini AF (1983) Determining simple parameters for social classifications for health research. Bull High Inst Public Health 13(5):95-108

10. Sheehan DV, Janavs J (1998) Mini International Neuropsychiatric Interview for Children / Adolescents (M.I.IN.I. Kid). University of South Florida, College of Medicine, Tampa

11. Ghanem MH, Ibrahim M, El-Behairy AA, El-Merghany H (1999) Mini International Neuropsychiatric Interview for Children / Adolescents (M.I.N.I. Kid); Arabic version (1st edition). Ain-Shams University, Institute of Psychiatry, Cairo

12. Roid JH (2003) Stanford-Binet Intelligence Scale (5 $5^{\text {th }}$ Edition). Riverside Publishing, Itasca, IL

13. Farag S (2011) The Stanford-Binet Intelligence Scale: Arabic examiner's handbook, 5th edn. Anglo Egyptian Bookshop, Cairo

14. Conners CK (1997) Conners' Rating Scales-revised technical manual. MultiHealth Systems, Inc., Toronto, Ontario

15. El-Sheikh MM (2003) Psychiatric morbidity in first degree relatives of a sample of ADHD children. Faculty of Medicine, Ain Shams University, Cairo, Dissertation

16. Achenbach T (1991) Manual for the child behavior checklist / 4-18 and 1991 profiles. University of Vermont, Department of psychiatry, Burlington VT

17. Sobhy SM. The impact of parental attitudes and parents' socio-cultural level on the development of creativity in children. Dissertation, Faculty of Education, Ain Shams University, Cairo (in Arabic), 1975.

18. Chang LR, Chiu YN, Wu YY, Gau SS (2013) Father's parenting and fatherchild relationship among children and adolescents with attention-deficit/ hyperactivity disorder. Compr Psychiatry 54(2):128-140

19. Gau SS, Chang JP (2013) Maternal parenting styles and mother-child relationship among adolescents with and without persistent attentiondeficit/hyperactivity disorder. Res Dev Disabil 34(5):1581-1594

20. Johnston C (1996) Parent characteristics and parent-child interactions in families of nonproblem children and ADHD children with higher and lower levels of oppositional-defiant behavior. J Abnorm Child Psychol 24(1):85-104

21. Keown $L$, Woodward $L J$ (2002) Early parent-child relations and family functioning of preschool boys with pervasive hyperactivity. J Abnorm Child Psychol 30(6):541-553.

22. Gerdes AC, Hoza B, Arnold LE et al (2007) Child and parent predictors of perceptions of parent-child relationship quality. J Atten Disord 11(1):37-48.

23. Ellis B, Nigg J (2009) Parenting practices and attention-deficit/hyperactivity disorder: new findings suggest partial specificity of effects. J Am Acad Child Adolesc Psychiatry 48:146-154.

24. Harty SC, Galanopoulos S, Newcorn JH, Halperin JM (2013) Delinquency, aggression, and attention-related problem behaviors differentially predict adolescent substance use in individuals diagnosed with ADHD. Am J Addict 22(6):543-550

25. Zenglein $Y$, Schwenck C, Westerwald E et al (2016) Empirically determined, psychopathological subtypes in children with ADHD. J Atten Disord 20(2): 96-107

26. Teixeira MC, Marino RL, Carreiro LR (2015) Associations between inadequate parenting practices and behavioral problems in children and adolescents with attention deficit hyperactivity disorder. Sci World J 2015:683062

27. Ni HC, Gau SS. Co-occurrence of attention-deficit hyperactivity disorder symptoms with other psychopathology in young adults: parenting style as a moderator. Compr Psychiatry 2015;57: 85-96.

28. Pfiffner $L$, McBurnett K, Rathouz PJ, Judice S (2005) Family correlates of oppositional and conduct disorders in children with attention deficit/ hyperactivity disorder. J Abnorm Child Psychol 33(5):551-563

29. Gerdes AC, Hoza B, Pelham WE (2003) Attention-deficit/hyperactivity disordered boys relationships with their mothers and fathers: child, mother, and father perceptions. Dev Psychopathol 15(2):363-382 
30. Owens JS, Goldfine ME, Evangelista NM, Hoza B, Kaiser NM (2007) A critical review of self-perceptions and the positive illusory bias in children with ADHD. Clin Child Fam Psychol Rev 10(4):335-351

31. McQuade JD, Mendoza SA, Larsen KL, Breaux RP. The nature of social positive illusory bias: reflection of social impairment, self-protective motivation, or poor executive functioning? J Abnorm Child Psychol2017; 45(2): 289-300

32. Hoza B, Waschbusch DA, Pelham WE, Molina BSG, Milich R (2000) Attentiondeficit/hyperactivity disordered and control boys' responses to social success and failure. Child Dev 71(2):432-446

33. Diener MB, Milich R (1997) Effects of positive feedback on the social interactions of boys with attention deficit hyperactivity disorder: a test of the self-protective hypothesis. J Clin Child Psychol 26(3):256-265

34. Linnea K, Hoza B, Tomb M, Kaiser N (2012) Does a positive bias relate to social behavior in children with ADHD? Behav Ther 43(4):862-875

35. Swanson EN, Owens EB, Hinshaw SP (2012) Is the positive illusory bias illusory? Examining discrepant self-perceptions of competence in girls with ADHD. J Abnorm Child Psychol 40(6):987-998

36. Emeh CC, Mikami AY (2014) The influence of parent behaviors on positive illusory bias in children with ADHD. J Atten Disord 18(5):456-465

37. Molina MF. Perceived parenting style and self-perception in children with attention deficit/hyperactivity disorder. Int J Psychol Res (Medellin)2015;8(1): 61-74.

38. Jia M, Jiang Y,Mikami AY. Positively biased self-perceptions in children with ADHD: unique predictor of future maladjustment. J Abnorm Child Psychol2016:44(3): 575-586.

39. Volz-Sidiropoulou E, Boecker M, Gauggel S (2016) The positive illusory bias in children and adolescents with ADHD: further evidence. J Atten Disord 20(2):178-186

40. Capodieci A, Crisci G, Mammarella IC (2018) Does positive illusory bias affect self-concept and loneliness in children with symptoms of ADHD? J Atten Disord 1:1087054718763735 (in press)

41. Emeh CC, Mikami AY, Teachman BA (2018) Explicit and implicit positive illusory bias in children with ADHD. J Atten Disord 22(10):994-1001

42. Hoza B, Pelham WE Jr, Dobbs J, Owens JS, Pillow DR (2002) Do boys with attention-deficit/hyperactivity disorder have positive illusory self-concepts? J Abnorm Child Psychol 111(2):268-278

43. Hoza B, Gerdes AC, Hinshaw SP et al (2004) Self-perceptions of competence in children with ADHD and comparison children. J Consult Clin Psychol 72(3):382-391

\section{Publisher's Note}

Springer Nature remains neutral with regard to jurisdictional claims in published maps and institutional affiliations.

\section{Submit your manuscript to a SpringerOpen ${ }^{\circ}$ journal and benefit from:}

- Convenient online submission

- Rigorous peer review

- Open access: articles freely available online

- High visibility within the field

- Retaining the copyright to your article

Submit your next manuscript at $\boldsymbol{\nabla}$ springeropen.com 